\title{
Comparison of temporal and kinetic walking parameters among young people and falling and non-falling elderly persons
}

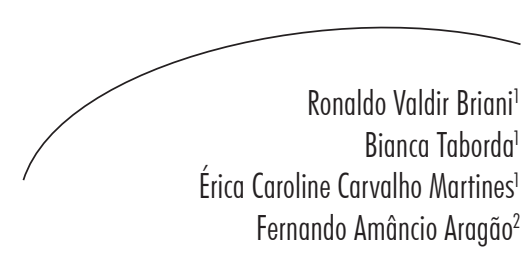

Abstract

Objective: Comparison of the biomechanical parameters (spatiotemporal and kinetic) during walking of young people, falling, and non-falling elderly persons. Methods: A cross-sectional study was performed of 29 individuals divided into three groups: young persons $(n=10)$; falling elderly individuals $(n=7)$ and non-falling individuals $(n=12)$. Gait analysis was performed based on the recording of three walking gait cycles along an 8 meter platform, which was attached to a force plate with a recording frequency of 200 Hz. Gait cycles were also recorded by three video cameras positioned perpendicular to the force plate with a recording frequency of $60 \mathrm{~Hz}$. The data analyzed was: average step velocity, stance time, Froude number and anteroposterior ground reaction force. Results: The average step velocity was higher among young persons and there was no difference in the Froude number among the three groups. During the stance and impulse phase,

Key words: Elderly; Accidental Falls; Gait. anterior and posterior force was higher among young persons than in the non-falling elderly group. The foot stance time of young individuals was also lower than the nonfalling elderly group $(\mathrm{p}=0.000)$ and the foot stance time of the falling elderly group was lower than that of the non-falling elderly group $(p=0.004)$. Conclusion: Falling and non-falling elderly persons have different gait biomechanical characteristics than young women, other than with respect to the Froude number. Furthermore, falling elderly persons spend more time in the gait swing phase than non-falling elderly persons.

\footnotetext{
Universidade Estadual do Oeste do Paraná, Centro de Ciências Biológicas e da Saúde, Curso de Fisioterapia. Cascavel, PR, Brasil.

2 Universidade Estadual do Oeste do Paraná, Laboratório de Pesquisa do Movimento Humano - LAPEMH, Centro de Ciências Biológicas e da Saúde, Curso de Fisioterapia. Cascavel, PR, Brasil. 


\section{INTRODUCTION}

The aging process involves a number of deficiencies that accumulate over a lifetime in the various systems of the body. Gait is not immune to the cumulative deficiencies of aging, and is affected by the gradual reduction of the efficiency of the locomotor system, which is caused by a number of factors including reduced muscle strength and limb flexibility. Thus, the occurrence of falls in the elderly is common, resulting in the increased morbidity and mortality of this population., ${ }^{1,2}$

According to Siqueira et al., $34 \%$ of elderly individuals older than 60 have suffered from falls, and of these, $17.9 \%$ had their usual daily activities restricted by the event. Following the first fall, approximately $50 \%$ of these elderly individuals became recurring fallers, with two or more events every 12 months. ${ }^{4}$ Among elderly fallers, the female population stands out due to the high rate of falls in this group. Recently, a prospective study accompanied 1,044 women who were aged older than 75 for ten years, of whom 427 (41\%) suffered some type of fracture due to falls in this period. ${ }^{5}$ While the causes of falls are multifactorial, more than $50 \%$ of falls occur during walking. ${ }^{4}$

Despite the gait of elderly persons being a widely discussed theme, to date few studies exist in literature that characterize and compare the biomechanical differences in the walking of younger women, falling elderly women and nonfalling elderly women. Due to the increase in the morbidity and mortality rates of elderly women who become recurring fallers, ${ }^{2,3}$ a study that identifies altered and/or exacerbated biomechanical parameters in comparison with those observed in non-falling elderly women and younger women could provide important information regarding treatment approaches for this population.

The aim of this study was therefore to compare the spatiotemporal and kinetic biomechanical parameters of the gait of young women, elderly female fallers and elderly female non-fallers, in an attempt to identify differences in the gait patterns of these three groups of individuals.

\section{METHODOLOGY}

A case-control cross sectional study of a sample of 29 intentionally selected female subjects was performed. The subjects were divided into three groups: the Young Group (Young), consisting of healthy individuals aged 18 to 23 years $(\mathrm{n}=10)$; the Elderly Fallers Group (Elderly F), comprising individuals considered to be fallers aged between 60 and 75 years $(n=7)$; and the Elderly NonFallers Group (Elderly NF), made up of healthy individuals deemed to be non-fallers aged between 60 and 75 years $(n=12)$.

Based on a retrospective study that indicated a prevalence of falls greater than $70 \%$ among women, ${ }^{6}$ only female subjects with ages compatible with the groups were selected. To be included in the "Young" and "Elderly NF" groups individuals could not have suffered a fall in the 12 months preceding the assessment, and be aged between 18 and 23 years, and 60 and 75 years, respectively. Individuals in the "Elderly F" group had to have suffered at least two falls in the 12 months prior to the beginning of the study and be aged between 60 and 75 years; adopting the criteria of Whitney et al. ${ }^{7}$

Individuals were not included in the sample if they (1) had a diagnosed neurological disease (2) had difficulty walking, including the use of mobility aids such as crutches, canes or walkers of any kind (3) had diagnosed, uncorrected visual deficits; (4) had orthopedic diseases that would make performing the tests impossible; (5) suffered from dizziness and/or uncontrolled chronic vestibular disorders; (6) used medications with documented effects on balance and gait (sedatives, tranquilizers, antidepressants or antiarrhythmic agents); (7) suffer 
from other serious musculoskeletal injuries or pain of any kind which could influence gait quality.

Before data collection began, all the participants signed a Free and Informed Consent Form approved by the Ethics Research Committee of the Universidade Estadual do Oeste do Paraná (registration $n^{\circ}$ 047/2011). Data was collected between August and December 2011.

An identification form was used to record the following information from participants: personal data; anthropometric measurements (height and limb length, or in other words the distance from the greater trochanter of the femur through the articular line of the knee, from the lateral malleolus to the ground $)^{8}$ information about the health of participants (illness, injury, medications used) and information on matters relating to a history of falls or the absence of such a history.

During the assessment procedure, participants walked down an eight meter long walkway which had a force plate (OR6-6 AMTI, USA) with dimensions of $46.4 \mathrm{~cm} \times 50.8 \mathrm{~cm}$ positioned in the middle to allow the measurement of kinetic data related to ground reaction forces. The walking platform and the force plate were covered with a $6 \mathrm{~mm}$ thick hard black rubber cover, which prevented identification of the position of the force plate during walking.

To familiarize the participants with the test, five simulations were performed, in which they walked the eight meter distance naturally. Participants were instructed to walk barefoot at the speed they would use when walking comfortably on a daily basis (this speed was chosen by the patients). Only tests in which participants completed the eight meter course and made full contact with their right foot within the force plate boundaries were recorded, with a maximum of three attempts being recorded. The presence of the force plate and the need to complete the stance phase within the same were not revealed to the participants, and the simulation was performed immediately prior to data collection so that it could not be identified by the study participants.

The kinetic data was collected through a force plate with a sampling frequency of $200 \mathrm{~Hz}$, using the AMTI NetForce ${ }^{\circledR}$ program, and was analyzed with the AMTI Bioanalisys ${ }^{\circledR}$ program (AMTI, USA). Force was measured in the anterior posterior direction. During the stance and momentum phase of gait there exist two peaks, namely: (1) peak force exerted when the heel makes contact with the ground (friction force and deceleration) which is part of the Stance Phase (SP) and (2) the peak force exerted by the forefoot on the plate (momentum force) which is part of the Momentum Phase (MP). The total support time in which the foot remained in contact with the force plate was also analyzed.

The gait cycles (attempts) were recorded by three conventional high-resolution video cameras (NVGS180 3CCD, Panasonic Co. Japan), positioned perpendicular to the force plate. The cameras were positioned at a distance $2.5 \mathrm{~m}$ away from the plate and at the height of the axis of the hip, knee, and ankle joints, respectively, of each participant, so that images of the movement of the right lower limb and the torso could be collected. Video data was collected with the Virtual Dub software package (v 0.9.11, Microsoft Visual Studio) with a sampling frequency of $60 \mathrm{~Hz}$.

The average gait speed was also measured. This represented the moment in which the right leg made contact with the force plate. In this way, the average gait speed could be measured at the time the participant was crossing the force plate.

To identify variability in mean gait speeds the Froude number technique was used. ${ }^{9}$ This technique is based on studies that found that lower limb size influences the natural walking speed of the subjects (which is selected by the subjects) 
and therefore aims to identify the variability of the speed of the participants in proportion to the size of their legs. ${ }^{10}$

Speed is capable of influencing the different kinetic and kinematic variables of gait, even when all the participants have been informed that they can walk at their preferred speed (chosen by the participant). For data analysis, therefore, ground reaction force was normalized by average gait speed. This mathematical procedure was carried out so that the kinetic variables of the groups could be compared, in order to minimize the effects of the differences in speed of each participant.

To analysis the study data, the Shapiro-Wilk test was initially applied to confirm the normality of the variables. Then ground reaction force, support time, Froude number and mean gait speed underwent analysis variance (ANOVA one way) followed by the post-hoc Bonferroni test to identify possible differences between groups. All statistical analysis used the $\underline{\text { SPSS }}$ v.17 (Statistical Package for the Social Sciences) software program and adopted a $\mathrm{p}$ value of $\alpha \leq 0.05$.

\section{RESULTS}

The Shapiro-Wilk test confirmed the normality of the data analyzed, which was capable of being represented by mean and standard deviation. The results in relation to the demographic characteristics of the sample are shown in table 1.

Table 1. Demographic characteristics of the Young, Elderly Faller (Elderly F) and Elderly Non-faller (Elderly NF) groups. Cascavel, PR, 2012.

\begin{tabular}{cccc}
\hline Parameters & Young persons & Elderly F. & Elderly NF. \\
\hline Age (years) & $21.91( \pm 2.72)$ & $69.74( \pm 0.98)$ & $71.25( \pm 1.65)$ \\
Height $(\mathrm{m})$ & $1.65( \pm 0.05)$ & $1.63( \pm 0.04)$ & $1.68( \pm 0.07)$ \\
Weight $(\mathrm{kg})$ & $65.72( \pm 10.76)$ & $72.51( \pm 8.64)$ & $70.37( \pm 6.71)$ \\
\hline
\end{tabular}

The mean gait speed of the Young Group was greater than that of both the Elderly NF Group and the Elderly F Group ( $p=0.004)$. However, the Froude number did not differ significantly between the groups $(p=0.087)$ (Figure 1).
During the SP, force in the anterior direction was greater in the Young Group than the Elderly NF group ( $p=0.021)$ (Figure 2). Similarly, during the MP, posterior force was greater in the Young Group than the Elderly NF Group. ( $p=0.001)$. 


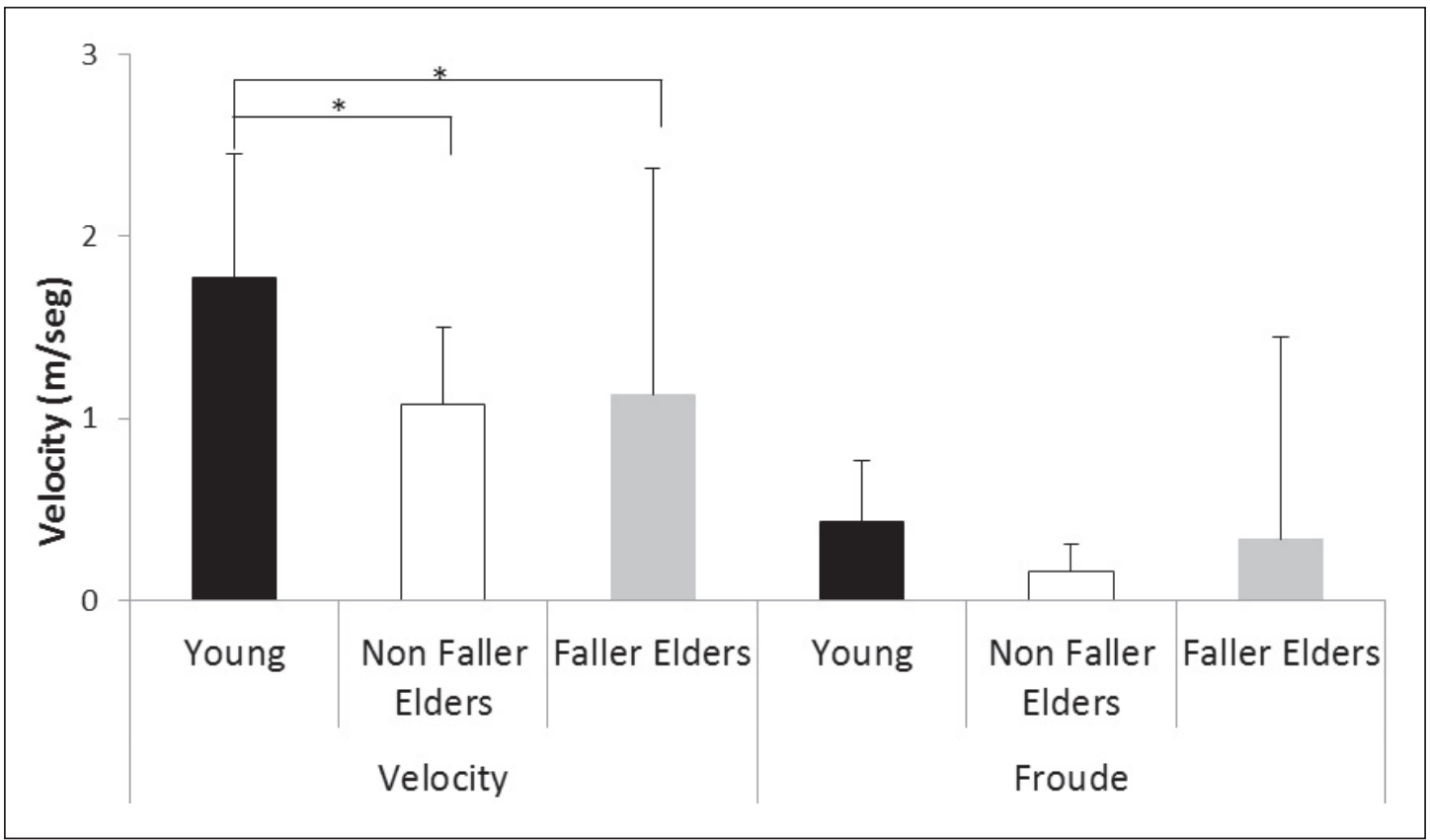

$*$ Representa as diferenças significativas encontradas entre os grupos $(p<0,05)$.

Figure 1. Mean and standard-deviation of average speed walking exercise and Froude number for Young, Elderly Faller (Elderly F.) and Elderly Non-Faller (Elderly NF.) groups. Cascavel, PR, 2012.



*Representa as diferenças significativas encontradas entre os grupos $(p<0,05)$.

Figure 2. Mean and standard-deviation of anterior and posterior soil reaction force for Young, Elderly Faller (Elderly F.) and Elderly Non-Faller (Elderly NF.) groups. Cascavel, PR, 2012. 
The means and standard deviations of the support time variables were: $0.62 \pm 0.03$ s., $0.77 \pm 0.14$ s. and $0.67 \pm 0.09$ s. for the Young, Elderly NF and Elderly F Groups, respectively. The Young Group had a shorter support time than the Elderly $F$ $(\mathrm{p}=0.000)$ and the Elderly NF $(\mathrm{p}=0.000)$ groups. The support time of the Elderly F Group was shorter than that of the Elderly NF Group. ( $p=0.004)$.

\section{DISCUSSION}

Just as various diseases, and even natural aging, can alter mobility and muscle efficiency, so there are many common types of compensatory gait reactions that attempt to maintain the functionality of locomotion. ${ }^{11}$ The present study sought to compare the biomechanical parameters related to the temporal and kinetic variables of gait among young women, non-falling elderly women and falling elderly women. In general, the variables studied showed differences in gait pattern between the young women group and the group of elderly women, taken as a whole. However, different walking patterns could not be identified between the group of elderly women defined as fallers and those classified as non-fallers, except for the difference in support time.

The present study used the Froude number in order to identify differences in gait speed between the groups, as this is a variable that involves anthropometric characteristics in the calculation of a relative speed index. Moretto et al., ${ }^{9}$ for example, demonstrated that the Froude number is an effective method of establishing dynamic similarities between subjects with different anthropometric characteristics. However, similar Froude number values were found for all the groups in the present study, showing that, even with differences in absolute speed, once standardized by their anthropometric characteristics, the groups had similar relative values. These results therefore demonstrate a dynamic similarity among the gait of young women, elderly falling women and elderly non-falling women.
The Froude number for each group remained close to optimum walking speed values. Optimum walking speed is defined as a speed that results in the largest conversion of energy by the inverted pendulum mechanism at the minimum metabolic cost. ${ }^{12}$ It can therefore be stated that even among the elderly women with a lower gait speed than the younger women, this speed is close to the walking speed considered to be physiological.

This decrease in speed can also be considered a protective factor for falls developed by the elderly and not necessarily the mechanism that causes the same.${ }^{13}$ For Kirkwood et al..${ }^{14}$ the muscle weakness, decreased mobility, muscle stretching and changes in lower limb support time caused by the aging process, can affect the stability of the elderly in movement, resulting in alternatives to compensate for such changes.

Overall, the elderly women had a greater leg support time than the younger people. Prolonged contact of the ankle with the ground to avoid body weight transfer to the forefoot is common, and is usually a sign of weakness of the gastrocnemius and soleus muscles. ${ }^{15,16}$ Previous studies have demonstrated the importance of this musculature for maintaining balance. ${ }^{17,18}$ Thus, a change in the strength of these muscles could lead to impaired balance and increased propensity to falls.

The Elderly F group had a lower leg support time than the Elderly NF group. In contrast, the average speed required to complete the walk did not differ between the two groups of elderly women. One possibility to explain this finding is that elderly fallers spend, during the walking activity, more time in the swing phase, which could increase instability during walking.

This study has limitations that must be mentioned. First, although a greater incidence of falls has been identified among the female population, this study did not include men, which limits the extrapolation of the data for this population. Next, the small size of the sample may have influenced or introduced tendencies in the 
results of this study. Finally, the kinematics of the lower limbs were not evaluated here, even though such a study could produce relevant information about the mechanics of the lower limbs. It is therefore suggested that future studies use 3D kinematic systems for assessing gait among the elderly in general.

\section{CONCLUSION}

The average gait speed and the ground reaction force in the anterior and posterior direction were higher for the young women than for the elderly falling and non-falling women. On the other hand, support time was shorter for the young women than for the other groups. The Froude number was similar for the three groups. From these findings it can be concluded that despite the biomechanical differences between young and old, all three groups performed the task in the most efficient way in relation to their physiological characteristics.

In relation to the comparison between the elderly fallers and non-fallers, the groups obtained similar values of mean gait speed, anterior and posterior ground reaction force and Froude number. Only support time was lower among the falling elderly women than in the non-falling elderly women. Therefore, considering these results, elderly fallers remain in the swing phase for longer, a fact that increases instability during walking and makes them more prone to further falls.

\section{REFERENCES}

1. Albino ILR, Freitas CDLR, Teixeira AR, Gonçalves AK, Santos AMPV Dos, Bós AJG. Influência do treinamento de força muscular e de flexibilidade articular sobre o equilíbrio corporal em idosas. Rev Bras Geriatr Gerontol 2012;15(1):17-25.

2. Batista FS, Gomes GAO, Neri AL, Guariento ME, Cintra FA, De Sousa MLR, et al. Relationship between lower-limb muscle strength and frailty among elderly people. São Paulo Med J 2012;130(2):102-8.

3. Siqueira FV, Silva D, Piccini RX, Tomasi E, Thumé E. Prevalence of falls in elderly in Brazil: a countrywide analysis. Cad saúde pública 2011;27(9):1819-26.

4. Brach JS, Perera S, Van Swearingen JM, Hile ES, Wert DM, Studenski S A. Challenging gait conditions predict 1-year decline in gait speed in older adults with apparently normal gait. Phys Ther 2011;91(12):1857-64.

5. Wihlborg A, Englund M, Åkesson K, Gerdhem P. Fracture predictive ability of physical performance tests and history of falls in elderly women: a 10-year prospective study. Osteoporosis Int 2015;26(8):2101-9.

6. Williams N, Hardy BM, Tarrant S, et al. Changes in hip fracture incidence, mortality and length of stay over the last decade in an Australian major trauma center. Arch Osteoporos 2013;8:1-2.
7. Whitney JC, Lord SR, Close JCT. Streamlining assessment and intervention in a falls clinic using the Timed Up and Go Test and Physiological Profile Assessments. Age Ageing 2005;34(6):567-71.

8. De Oliveira SD, Briani RV, Pazzinatto MF, Ferrari $\mathrm{D}$, Aragão FA, De Albuquerque CE, et al. Reliability and differentiation capability of dynamic and static kinematic measurements of rearfoot eversion in patellofemoral pain. Clin Biomech 2015;30(2):144-8.

9. Moretto P, Bisiaux M, Lafortune MA. Froude number fractions to increase walking pattern dynamic similarities: application to plantar pressure study in healthy subjects. Gait Posture 2007;25(1):40-8.

10. Leurs F, Ivanenko YP, Bengoetxea A, Cebolla AM, Dan B, Lacquaniti F, et al. Optimal walking speed following changes in limb geometry. J Exp Bio 2011;214(Pt 13):2276-82.

11. Mann L, Francisco J, Teixeira CS, Mota CB. A marcha humana: investigação com diferentes faixas etárias e patologias. Motriz 2008;14(3):346-53.

12. Saibene F, Minetti AE. Biomechanical and physiological aspects of legged locomotion in humans. Eur J Appl Physiol 2003;88(4-5):297-316.

13. Baird JL, Van Emmerik REA. Young and older adults use different strategies to perform a standing turning task. Clin Biomech 2009;24(10):826-32. 
14. Kirkwood RN, Araújo PA, Dias CS. Biomecânica da marcha em idosos caidores e não caidores: uma revisão da literatura. Rev Bras Ciênc Mov 2006;14(4):103-10.

15. Antero-jacquemin JS, Santos P, Garcia PA, Dias RC, Marcos J, Dias D. Comparação da função muscular isocinética dos membros inferiores entre idosos caidores e não caidores. Fisioter Pesqui 2012;19(1):39-44.

16. Leite LEA, Resende TL, Nogueira GM, Cruz IBM, Schneider RH, Gottlieb MGV. Envelhecimento, estresse oxidativo e sarcopenia: uma abordagem sistêmica. Rev Bras Geriatr Gerontol 2012;15(2):365-80.

17. Tokuno CD, Carpenter MG, Thorstensson A, Garland SJ, Cresswell AG. Control of the triceps surae during the postural sway of quiet standing. Acta Physiol 2007;191(3):229-36.

18. Tokuno CD, Garland SJ, Carpenter MG, Thorstensson A, Cresswell AG. Sway-dependent modulation of the triceps surae H-reflex during standing Corresponding author: J Appl Physiol 2008;104(5):1359-65.

Received: August 10, 2014

Revised: April 21, 2015

Accepted: June 23, 2015 